\title{
Nipah Virus Contamination of Hospital Surfaces during Outbreaks, Bangladesh, 2013-2014
}

\author{
Md Zakiul Hassan, Hossain M.S. Sazzad, Stephen P. Luby, Katharine Sturm-Ramirez, \\ Mejbah Uddin Bhuiyan, Mohammed Ziaur Rahman, Md Muzahidul Islam, Ute Ströher, \\ Sharmin Sultana, Mohammad Abdullah Heel Kafi, Peter Daszak, Mahmudur Rahman, Emily S. Gurley
}

Nipah virus (NiV) has been transmitted from patient to caregivers in Bangladesh presumably through oral secretions. We aimed to detect whether NiV-infected patients contaminate hospital surfaces with the virus. During December 2013-April 2014, we collected 1 swab sample from 5 surfaces near NiV-infected patients and tested surface and oral swab samples by real-time reverse transcription PCR for NiV RNA. We identified 16 Nipah patients; 12 cases were laboratory-confirmed and 4 probable. Of the 12 laboratoryconfirmed cases, 10 showed NiV RNA in oral swab specimens. We obtained surface swab samples for 6 Nipah patients; 5 had evidence of NiV RNA on $\geq 1$ surface: 4 patients contaminated towels, 3 bed sheets, and 1 the bed rail. Patients with NiV RNA in oral swab samples were significantly more likely than other Nipah patients to die. To reduce the risk for fomite transmission of NiV, infection control should target hospital surfaces.

$\mathrm{N}$ ipah virus $(\mathrm{NiV})$ is a batborne paramyxovirus $(1,2)$ that causes encephalitis in humans. NiV has caused outbreaks almost every year in Bangladesh since 2001; the case-fatality rate is $>70 \%$ (3). The 2 primary pathways of $\mathrm{NiV}$ transmission in Bangladesh are drinking raw date palm sap contaminated with excretions from Pteropus spp. fruit bats and human-to-human transmission through close contact with infected persons (4-7). Nearly one third of identified Nipah patients in Bangladesh were infected through person-to-person transmission (8); most of these were family caregivers who provided hands-on care to Nipah patients at home and in hospital $(3,6,9,10)$.

Author affiliations: icddr,b, Dhaka, Bangladesh (M.Z. Hassan, H.M.S. Sazzad, K. Sturm-Ramirez, M.U. Bhuiyan, M.Z. Rahman, M.M. Islam, M.A.H. Kafi, E.S. Gurley); Stanford University, Stanford, California, USA (S.P. Luby); Centers for Disease Control and Prevention, Atlanta, Georgia, USA (K. Sturm-Ramirez, U. Ströher); Institute of Epidemiology, Disease Control and Research, Dhaka (S. Sultana, M. Rahman); EcoHealth Alliance, New York, New York, USA (P. Daszak)

DOI: https://doi.org/10.3201/eid2401.161758
Transmission of NiV in hospital settings was first identified in 2001 during an outbreak in Siliguri, India, and in several outbreaks in Bangladesh since 2004 (6,9,11-13). In the outbreak in Siliguri, 66 persons were infected, and of the 60 for whom exposure was known, 45 (75\%) acquired infection during their hospital stay (11 patients admitted for other illness, 25 hospital staff, and 8 persons who visited an infected patient) (11). In Bangladesh, during the 2010-2011 Nipah outbreak, 2 hospital staff (1 physician, 1 hospital cleaner) were infected $(12,13)$.

NiV RNA has repeatedly been identified in infected patients' oral secretions $(14,15)$, and epidemiologic evidence suggests that exposure to respiratory secretions is a likely route of $\mathrm{NiV}$ transmission from patient to caregiver (6). In 2004, during an NiV outbreak with person-to-person transmission in Bangladesh, NiV RNA was found on a hospital wall near where an NiV patient received care (6).

Hospital wards in Bangladesh are often overcrowded with patients, family caregivers, and visitors and have a median of 4 persons $/ 10 \mathrm{~m}^{2}$ of floor space (16). The floor is often soiled with bodily secretions, and a median of 5 uncovered coughs or sneezes per $10 \mathrm{~m}^{2}$ per hour has been observed (16). Most wards have intermittent water supply, lack functioning handwashing stations, and have an inadequate number of toilets $(16,17)$. Hospital staff and family caregivers can acquire infections through direct patient contact or contaminated fomites $(18,19)$. Healthcare workers (i.e., doctors and nurses) have direct contact with patients; other staff, such as hospital cleaners, and visitors, who are not involved in patient care, might have contact only with hospital surfaces. Possible contamination of nearby hospital surfaces by Nipah patients with infectious bodily secretions, coupled with a lack of infection control measures in low-income hospitals, puts healthcare workers, caregivers, visitors, and other patients in the ward at risk for NiV infection by contaminated hospital surfaces. Propagation of a highly fatal pathogen with the capacity for person-to-person transmission within resource-constrained healthcare settings increases the risk for broader outbreaks $(11,20)$. 
In Bangladesh, resources for infection control in hospitals are severely limited (16), and we have limited knowledge about where to focus infection control to optimize use of scarce resources. Identification of fomites for possible $\mathrm{NiV}$ transmission would help design interventions prioritizing the area of hospital wards for disinfection to reduce surface contamination and possible risk for fomite transmission. Our objective was to identify whether Nipah patients contaminate nearby hospital surfaces with NiV RNA and, if so, which hospital surfaces are most commonly contaminated and which patients are most likely to contaminate their environment.

\section{Methods}

\section{Case Identification and Sample Collection}

We conducted this study in 3 Nipah surveillance hospitals at Faridpur, Rajshahi, and Rangpur, Bangladesh, during December 2013-April 2014. Surveillance physicians identified patients admitted with encephalitis, defined as fever or history of fever with axillary temperature $>38.5^{\circ} \mathrm{C}$ $\left(101.3^{\circ} \mathrm{F}\right)$ and altered mental status, new onset of seizures, or new neurologic deficit (21), and collected blood and oral swab samples. Because of resource constraints, surface sampling for all encephalitis cases was not possible; therefore, a research assistant swabbed hospital surfaces near encephalitis patients with a history of consuming raw date palm sap, contact with another encephalitis patient, or both (22). Occasionally, physicians from other nearby hospitals reported suspected Nipah case-patients to public health authorities. These patients also had biological samples collected for laboratory testing but were not included in the surface sampling study.

Blood samples were centrifuged at the local government health facility, and the separated serum was stored and transported to the Institute of Epidemiology Disease Control and Research laboratory in a liquid nitrogen dry shipper $\left(-150^{\circ} \mathrm{C}\right)$ and then stored at $-20^{\circ} \mathrm{C}$ until testing. From each patient, 1 oral swab was collected in $1 \mathrm{~mL}$ of nucleic acid extraction lysis buffer every consecutive day for 7 days, until hospital discharge or death, whichever occurred first.

A research assistant collected 1 swab sample from up to 5 areas near each patient: the wall beside patient bed, bed rail, bed sheet, clinical record file, and multipurpose towel used by family caregivers for cleaning patient secretions, drying hands, and other caregiving purposes. The research assistant collected surface swab samples at least 12 hours after the patient was admitted to the hospital. With 1 sterile rayon swab stick per surface, the research assistant swabbed the area of the wall in contact with the bed $45 \mathrm{~cm}$ high from the level of the bed sheet; all surfaces of the bed rail in the area near the patient's head; half of the bed sheet where the patient's head was, including underneath the patient; front and back covers of the patient file; and both sides of the multipurpose towel. Not all patients had a wall or bed rail near them because some patients were cared for on the floor and some were away from the walls. One swab sample per surface area was collected in separate cryovials with $1 \mathrm{~mL}$ of nucleic acid extraction lysis buffer (bioMérieux, Marcy-l'Étoile, France). The vials were kept in a cool box maintaining a temperature of $2^{\circ}-8^{\circ} \mathrm{C}$ for up to $30 \mathrm{~min}$ after collection and then were placed in a liquid nitrogen dry shipper for storage and transportation.

Testing of Clinical Samples and Surface Swab Samples Serum samples were tested for NiV IgM using an IgMcapture enzyme immunoassay (23). Oral and surface swab samples were tested for NiV RNA by real-time reverse transcription PCR (rRT-PCR). Viral RNA was extracted using a Kingfisher Flex 96 (Thermo Scientific, Waltham, MA, USA) automatic extractor using InviMagVirus DNA/ RNA Mini Kit/KF 96 (STRATEC Molecular, Birkenfeld, Germany). The rRT-PCR was performed on the CFX96 system (Bio-Rad, Inc., Hercules, CA, USA) and ABI7500 platform (Applied Biosystems, Foster City, CA, USA) using AgPath-ID One-Step RT-PCR Kit (Applied Biosystems). The following primers were used for detecting the NiV N gene: forward primer NVBNF2B 5'-CTGGTCTCTGCAGTTATCACCATC GA-3', reverse primer NVBN593R 5'-ACGTACTTAGCC CAT CTT CTA GTTTCA-3', and probe NVBN54P2 5'-Fam-CAG CTC CCGACACTGCCGAGG AT-BHQ-3' (24). To provide evidence that similar viruses were present in human specimens and the environmental swab samples, we performed PCR-based direct sequencing using nucleic acids obtained from patients' oral swab samples and their corresponding surface swab samples by using NiV-specific primers (online Technical Appendix Table 1, https://wwwnc.cdc.gov/ EID/article/24/1/16-1758-Techapp1.pdf). The sequencing was performed using the ABI Big Dye Terminator v3.1 Cycle Sequencing Kit in an automated ABI 3500 XL genetic analyzer (both from Applied Biosystems). Nucleotide sequence similarity searches were performed using BLAST (https://www.ncbi.nlm.nih.gov/BLAST/).

\section{Community Investigation}

An investigation team visited the communities of encephalitis patients identified at surveillance hospitals who had NiV IgM in serum to identify any other associated encephalitis cases. The team interviewed identified encephalitis patients and their caregivers using a structured questionnaire. Identified patients were asked about the nature of their contact with hospitalized patients (i.e., touching, being in the same room, feeding, sharing a bed, or cleaning body 
secretions) to find evidence of person-to-person transmission. The team also collected blood from the encephalitis patients identified in the community investigation.

\section{Classification of Cases}

We classified an encephalitis case as laboratory-confirmed Nipah in a patient with NiV IgM in serum and a probable Nipah case as a case with an epidemiologic link with a laboratory-confirmed Nipah case in a person who died before blood could be collected for testing. We defined a Nipah spreader as a person with a probable or confirmed case who had close contact with at least 1 person in whom Nipah illness developed 5-15 days after contact (5).

\section{Statistical Analysis}

We summarized the data using frequency and percentages. We assessed the difference in proportions using $\chi^{2}$ test or Fisher exact test when appropriate. We considered $p<0.05$ as statistically significant.

\section{Ethical Consideration}

Study participants or their legal guardian provided informed written consent. The Ethical Review Committee of icddr,b (Dhaka, Bangladesh) reviewed and approved the study protocol. The Institutional Review Board at the Centers for Disease Control and Prevention (Atlanta, GA, USA) deferred to icddr,b's approval.

\section{Results}

Surveillance physicians identified 332 encephalitis cases in the 3 surveillance hospitals. One encephalitis case was reported from a nearby hospital, and we identified an additional 2 encephalitis cases from the community investigations. Of the 332 encephalitis cases identified in surveillance hospitals, we tested blood samples and oral swab samples from 312 (94\%) case-patients and collected hospital surface swab samples from 49 case-patients who had a history of consuming raw date palm sap or contact with other encephalitis patients as reported by their caregiver on admission at the hospital. Of the 312 patients tested from surveillance hospitals, $9(3 \%)$ had NiV IgM. All 3 casepatients identified during community investigations were hospitalized at nonsurveillance hospitals, and all had detectable NiV IgM (Figure 1). Through the community investigation, we identified an additional 4 probable Nipah case-patients who died before specimens could be collected. Thus, we identified a total of 16 Nipah cases from hospital and community investigations. Four cases occurred in isolation, but 12 clustered in 4 outbreaks. The 4 clusters comprised 8 laboratory-confirmed and 4 probable cases. Two of the 4 clusters involved person-to-person transmission (online Technical Appendix).

Of the 12 case-patients with laboratory-confirmed Nipah, 10 (83\%) had NiV RNA in $\geq 1$ oral swab sample (Figure 2). We collected 19 oral swab samples from these

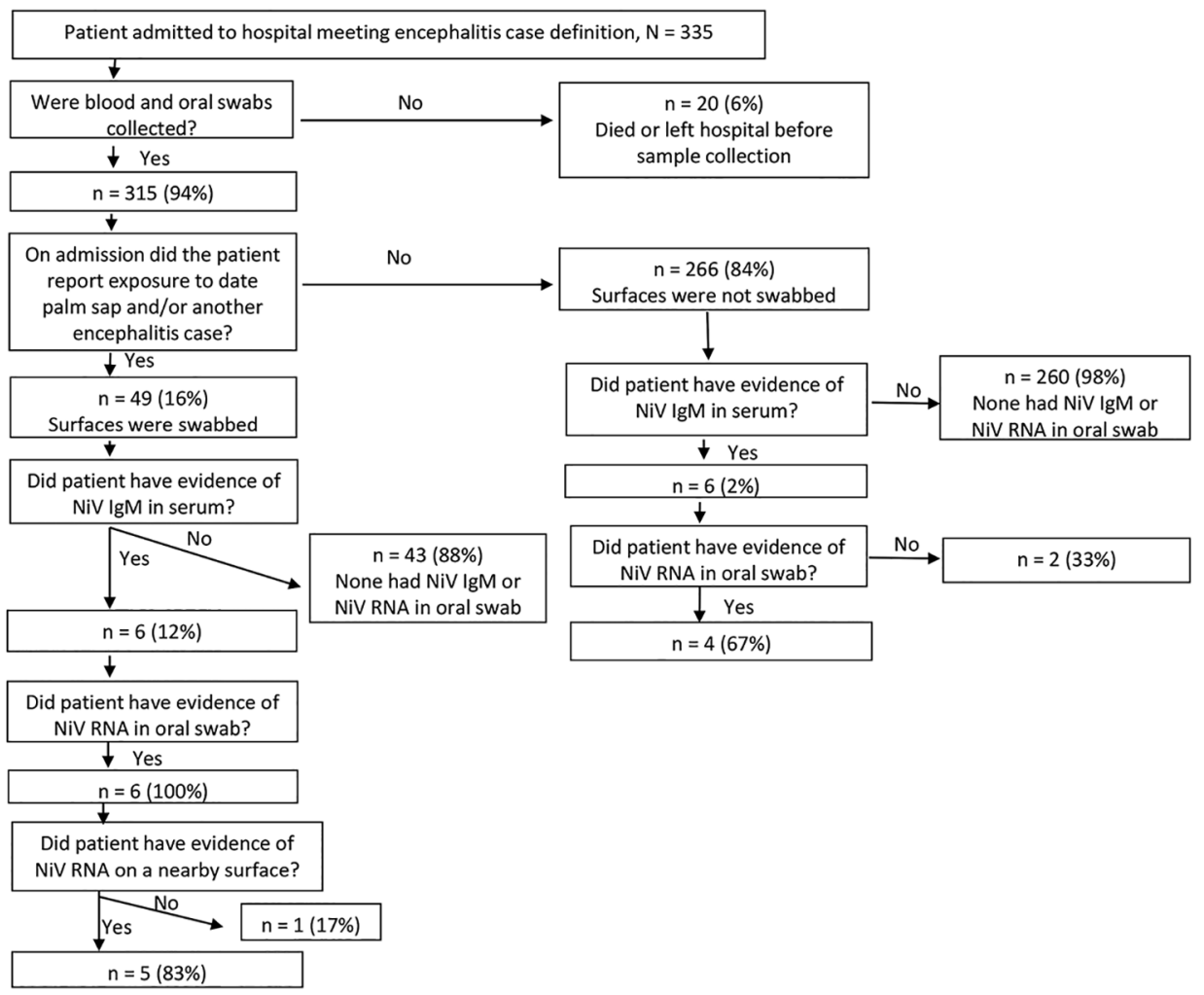

Figure 1. Number of blood samples, oral swab samples, and surface swab samples collected and tested from encephalitis patients identified in hospitals, Bangladesh, December 2013-April 2014. 
Table 1. Laboratory results of swab samples of 6 patients with detectable Nipah virus RNA from 3 surveillance hospitals, Bangladesh, December 2013-April 2014*

\begin{tabular}{|c|c|c|c|c|c|c|c|c|c|c|c|c|c|}
\hline \multirow[b]{5}{*}{ Patient } & \multicolumn{13}{|c|}{ Days after hospitalization collected and result } \\
\hline & \multirow{3}{*}{\multicolumn{3}{|c|}{ Oral swab sample }} & \multicolumn{10}{|c|}{ Surface swab sample } \\
\hline & & & & \multicolumn{5}{|c|}{1} & \multicolumn{5}{|c|}{2} \\
\hline & & & & \multirow[b]{2}{*}{ Towel } & \multirow[b]{2}{*}{ Bed sheet } & \multirow[b]{2}{*}{ Bed rail } & \multirow{2}{*}{$\begin{array}{l}\text { Clinical } \\
\text { file }\end{array}$} & \multirow[b]{2}{*}{ Walls } & \multirow[b]{2}{*}{ Towel } & \multirow[b]{2}{*}{ Bed sheet } & \multirow[b]{2}{*}{ Bed rail } & \multirow{2}{*}{$\begin{array}{l}\text { Clinical } \\
\text { file }\end{array}$} & \multirow[b]{2}{*}{ Walls } \\
\hline & 1 & 2 & 3 & & & & & & & & & & \\
\hline 1 & Pos & Pos & & & & & & & Pos & Neg & Pos & Neg & \\
\hline 2 & Pos & Pos & & & & & & & Pos & Pos & & Neg & Neg \\
\hline 3 & Pos & Pos & Pos & Pos & Pos & & Neg & Neg & & & & & \\
\hline 4 & Pos & & & & Pos & $\mathrm{Neg}$ & Neg & & & & & & \\
\hline 5 & Pos & Pos & & & & & & & Pos & Neg & Neg & Neg & Neg \\
\hline 6 & Pos & Pos & & Neg & Neg & Neg & $\mathrm{Neg}$ & Neg & & & & & \\
\hline
\end{tabular}

10 case-patients; all 19 samples had evidence of NiV RNA. None of the 303 patients identified at surveillance hospitals without NiV IgM in serum had detectable NiV RNA on an oral swab sample. Of the 49 patients identified in surveillance hospitals for whom surface swab samples were collected, 6 had laboratory-confirmed Nipah (Table 1). We did not collect nearby surface swab samples from the other laboratory-confirmed Nipah patients with detectable NiV RNA in oral swab samples because during hospital admission they reported no history of consuming raw date palm sap or contact with other encephalitis patients. All of the 6 laboratory-confirmed Nipah patients from whom we collected nearby surface swab samples had detectable NiV RNA in their oral swab samples, and 5 of these had evidence of NiV RNA on $\geq 1$ nearby surface. Of the 5 patients who contaminated nearby hospital surfaces, 4 contaminated their towels, 3 contaminated their bed sheets, and 1 contaminated the bed rail. We detected no evidence for $\mathrm{NiV}$ RNA-contaminated walls or clinical files (Table 2).

We retrieved data on the partial $\mathrm{N}$ gene sequence (361 bp) from 4 patients' oral swab samples and 3 surface swab samples surrounding 2 of these 4 patients: from the towel surface for 1 patient and the towel and bed rail for 1 patient (GenBank accession nos. KY887670-1, MF133373-6, and MF13337). The sequence recovery was $40 \%(4 / 10)$ for oral swab samples and 38\% (3/8) for surface swab samples. The sequences from patients' oral swab samples and corresponding surface swab samples were indistinguishable over the length of the sequenced fragments, and BLAST analysis indicated they were $>99 \%$ similar to that of the NiV sequences (GenBank accession nos. JN808857, JN808859, JN808860，JN808864，JN808862) reported from Bangladesh.

Our investigation identified 3 Nipah patients who were infected through person-to-person transmission. Two of these patients were infected by 1 probable case-patient who died before specimens were collected. The third casepatient had close contact with 2 laboratory-confirmed case-patients over the same time period, but we were unable to determine the source of infection. Both possible sources had evidence of NiV RNA in oral swabs; however, only 1 of the possible infectors contaminated the hospital surfaces and therefore might be more likely to be the infector (online Technical Appendix Table 2, Figure 1). Laboratory-confirmed Nipah patients with detectable NiV RNA in oral swab samples were more likely to die than were patients with undetectable NiV RNA (90\% [9/10] vs. $0 \%[0 / 2] ; p=0.04)$.

\section{Discussion}

Nipah patients frequently contaminated hospital surfaces near them with detectable NiV RNA, posing a risk for fomiteborne Nipah transmission. The most commonly contaminated surfaces were the bed sheets and the towels used by caregivers for patient care. In Bangladesh, family caregivers, rather than trained healthcare workers, provide 24 -hour hands-on care to hospitalized patients $(17,25)$. The more severe the patient's illness, the more hands-on care he or she receives (17). Most Nipah patients in Bangladesh are unconscious when they are brought in for care and have cough and difficulty breathing (21), requiring close attention and care. Nipah patients often dribble frothy oral secretions, soiling themselves and contaminating their bed sheets. Caregivers frequently use a towel brought from home to clean patient oral secretions (17) and often use the same towel throughout the hospital stay. They also frequently use the same towel for cleaning their own hands and face. The lack of running water in healthcare settings in Bangladesh makes it difficult for caregivers to wash their hands or wash the items used for patient care (16). One Nipah patient we identified was infected after caring for 2 other patients, 1 of whom had a towel contaminated with detectable NiV RNA, highlighting the possibility of this fomite as a vehicle of NiV transmission from patient to caregiver. The caregiver also contaminated nearby surfaces during his illness, including the towel, although no further transmission was evident.

We did not detect NiV RNA on the patient clinical file and nearby wall surfaces, most likely because of the distance and infrequency of contact of these surfaces with a patient's oral secretions. Although in Bangladesh hospitals patient clinical files are commonly kept on the bed or under 


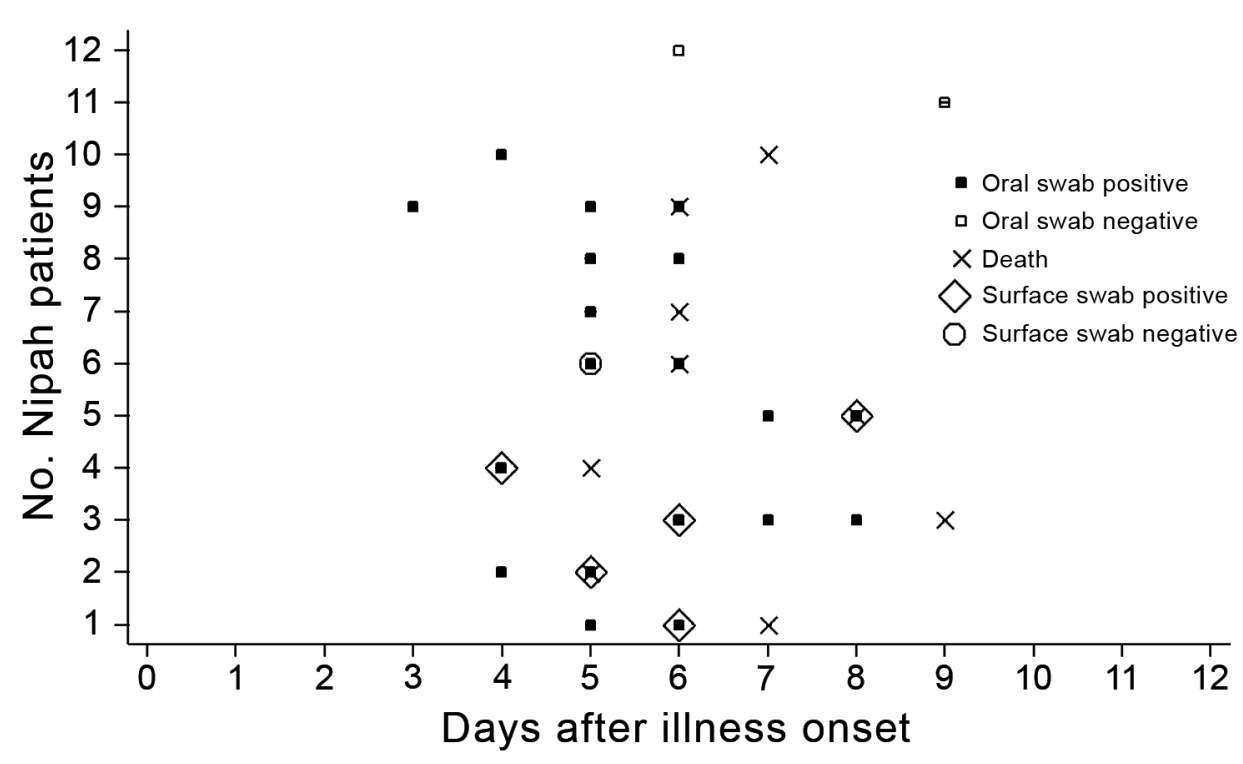

Figure 2. Timing of Nipah virus detection in oral swab and surface swab samples in relation to illness onset for 12 patients with laboratory-confirmed Nipah identified in hospitals, Bangladesh, December 2013April 2014. Nearby surface swabs were not collected for 6 patients (nos. 7-12). the bed sheet or pillow, they are also sometimes kept at the nurses' station, reducing the frequency of the file coming into contact with patient oral secretions. We also found that the walls were the surfaces farthest from the patient and for this reason might have been less frequently contaminated with oral secretions.

Transmission of NiV through fomites is plausible. Many paramyxoviruses, including respiratory syncytial virus, parainfluenza viruses $1-4$, and human metapneumoviruses, have been identified on hospital surfaces, and fomiteborne transmission of these pathogens has been reported (26-30). Past studies have indicated that other paramyxoviruses can survive on surfaces for up to 10 hours and be a source of infection for patients, healthcare workers, and hospital visitors (26,31-33). Animal experiments with $\mathrm{NiV}$ in a hamster model also showed that $\mathrm{NiV}$ can be transmitted through fomites (34). Although it is not known how long NiV remains infectious in the environment, we hypothesize that surfaces might play an important role in $\mathrm{NiV}$ transmission for several reasons: hospital surfaces in Bangladesh are not routinely cleaned (16); new patients frequently use the same bed sheets used by previous occupants (16); caregivers and healthcare workers frequently come into contact with contaminated surfaces (10); and handwashing by caregivers and healthcare workers occurs infrequently because of several barriers, including a lack of running water in hospitals $(16,17)$.

Investigations of earlier outbreaks showed that only $7 \%$ of all Nipah patients were Nipah spreaders $(5,35)$. During our 5-month study, we identified 16 Nipah patients and 2 likely spreaders. The 2 spreaders we identified both infected their primary caregivers (online Technical Appendix Table 2, Figure 1). This finding provides additional evidence that exposure to contaminated oral secretions drives person-to-person transmission of NiV. Caregivers can be exposed to oral secretions through direct patient contact, contaminated surfaces, or both. Family care providers maintained close physical contact with Nipah patients, including sharing eating utensils and drinking glasses, sleeping in the same bed, and hugging and kissing near the time of death, which highlights that contact transmission might play a major role in NiV transmission (36). Our investigation showed similar patterns of caregiving practices in this outbreak (online Technical Appendix Table 2). Reports from earlier outbreaks also demonstrated that Nipah patients who had respiratory involvement (difficulty breathing and cough) were more likely to become Nipah spreaders $(5,6,9,12)$. However, our current understanding is limited about why some Nipah patients shed $\mathrm{NiV}$ in their oral secretions (and for how long they shed) but others do not. Virus replication in the respiratory epithelium of hamsters infected with a high dose of $\mathrm{NiV}$ was 2 logs higher than in those infected with a low dose, suggesting dose of exposure might affect viral shedding in respiratory secretions (36). All NiV case-patients who had evidence of NiV RNA in their oral secretions died, and those without NiV RNA survived, suggesting that virulence also might be associated with tissue tropism or viral

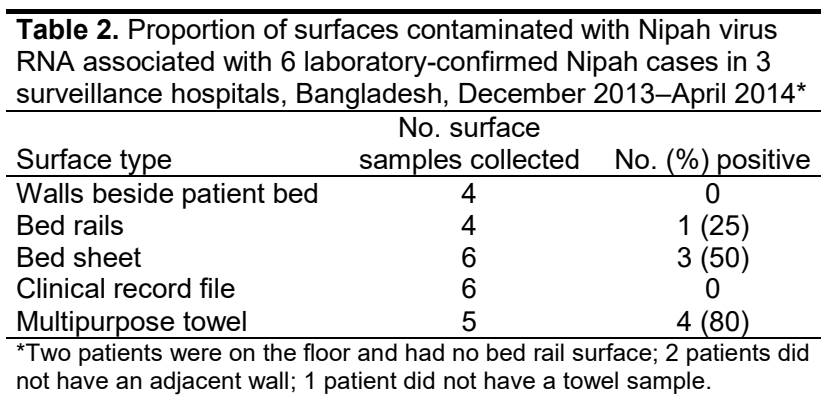


load. A better understanding of the factors that determine variations of viral shedding between Nipah patients might explain the drivers of person-to-person transmission of NiV. Given limited resources for infection control in low-income settings, early identification of patients who shed NiV could help focus resources to reduce subsequent transmission of NiV from person to person. NiV surveillance in Bangladesh relies on a central laboratory located in the capital city; thus, confirming a diagnosis can take several days or weeks and limits the ability for an early intervention. A rapid diagnostic test that could quickly identify NiV patients at the bedside could be a powerful tool in the early identification of potential NiV spreaders, formulating early intervention and thereby preventing $\mathrm{NiV}$ transmission in hospitals.

Our study had limited power to detect a significant difference in characteristics of patients with and without detectable NiV RNA in oral swabs because of the small number of laboratory-confirmed Nipah patients we identified. However, despite low power and small number of observations, we found a significant association between having detectable NiV RNA in an oral swab sample and dying from illness. In addition, although we identified NiV RNA on various surfaces, the presence of nucleic acid does not confirm contamination with a viable virus nor does it indicate that fomites are important for NiV transmission. However, laboratory evidence suggests that paramyxoviruses can survive on surfaces and have been a source of transmission in healthcare settings $(26,27)$. Studies on NiV survival in environmental condition have shown that $\mathrm{NiV}$ survival varies from a few hours to $\approx 2$ days and is highly dependent on $\mathrm{pH}$, temperature, and desiccation $(37,38)$. Previous studies suggest that persons at highest risk for infection from patients with $\mathrm{NiV}$ are family caregivers who provide continuous care, even during hospitalizations $(9,10,20)$. Therefore, even if the virus remains viable for only a short time, it still could pose a major risk for these caregivers.

Efforts to reduce the risk for person-to-person NiV transmission in healthcare settings should target patient caregiving practices related to the use of towels. Resources are limited for hospitals and for patients' families; however, affordable options exist that deserve additional investigation to determine their acceptability and feasibility. For example, families could be counseled to purchase a separate towel for patients, which costs $\approx \mathrm{US}$ $\$ 0.50$. Also, hospitals could provide low-cost disinfectants, such as $0.5 \%$ sodium hypochlorite, for $\approx$ US $\$ 1 /$ liter to use to disinfect towels and caregiver hands. We also advocate for the development of a rapid test to identify $\mathrm{NiV}$ patients, who represent only $\approx 3 \%$ of all encephalitis patients, to most efficiently focus infection control efforts for $\mathrm{NiV}$ prevention $(6,39,40)$.

\section{Acknowledgments}

We thank all the study participants and their family members for their support during the investigation. We also thank the hospital authority for its permission and cooperation and the study physicians, field staff, and laboratory staff for their contributions. We are indebted to Diana Diaz Granados for reviewing and editing this manuscript.

The study was funded by Centers for Disease Control and Prevention (CDC) cooperative agreement no. 5U01CI000628, US National Institutes of Health (NIH) grant no. 07-015-071252200 (Bangladesh-NIH/Emerging Infectious Diseases), and National Science Foundation/NIH Ecology and Evolution of Infectious Diseases grant no. 2R01-TW005869 from the Fogarty International Center. icddr,b acknowledges with gratitude the commitment of Centers for Disease Control and Prevention and $\mathrm{NIH}$ to its research effort. icddr,b is also grateful to the governments of Bangladesh, Canada, Sweden, and the United Kingdom for providing core/unrestricted support.

Mr. Hassan is a medical graduate working with the Programme for Emerging Infections, Infectious Diseases Division at the icddr,b. His research interests include infectious disease epidemiology, healthcare-associated infections, and control and prevention of emerging infections in resource-limited settings.

\section{References}

1. Bellini WJ, Harcourt BH, Bowden N, Rota PA. Nipah virus: an emergent paramyxovirus causing severe encephalitis in humans. J Neurovirol. 2005;11:481-7. http://dx.doi.org/10.1080/ 13550280500187435

2. Chua KB, Bellini WJ, Rota PA, Harcourt BH, Tamin A, Lam SK, et al. Nipah virus: a recently emergent deadly paramyxovirus. Science. 2000;288:1432-5. http://dx.doi.org/10.1126/ science. 288.5470 .1432

3. Luby SP, Gurley ES, Hossain MJ. Transmission of human infection with Nipah virus. Clin Infect Dis. 2009;49:1743-8. http://dx.doi.org/10.1086/647951

4. Luby SP, Gurley ES, Hossain MJ. Transmission of human infection with Nipah virus. Clin Infect Dis. 2009;49:1743-8. http://dx.doi.org/10.1086/647951

5. Luby SP, Hossain MJ, Gurley ES, Ahmed B-N, Banu S, Khan SU, et al. Recurrent zoonotic transmission of Nipah virus into humans, Bangladesh, 2001-2007. Emerg Infect Dis. 2009;15:1229-35. http://dx.doi.org/10.3201/eid1508.081237

6. Gurley ES, Montgomery JM, Hossain MJ, Bell M, Azad AK, Islam MR, et al. Person-to-person transmission of Nipah virus in a Bangladeshi community. Emerg Infect Dis. 2007;13:1031-7. http://dx.doi.org/10.3201/eid1307.061128

7. Gurley ES, Luby SP. Nipah virus transmission in South Asia: exploring the mysteries and addressing the problems. Future Virol. 2011;6:897-900. http://dx.doi.org/10.2217/fvl.11.70

8. Luby S, Gurley E. Epidemiology of henipaviruses. In: Shapshak P, Sinnott JT, Somboonwit C, Kuhn J, editors. Global virology I-identifying and investigating viral diseases. New York: Springer; 2015. p. 55-71.

9. Homaira N, Rahman M, Hossain MJ, Epstein JH, Sultana R, Khan MS, et al. Nipah virus outbreak with person-to-person transmission in a district of Bangladesh, 2007. Epidemiol Infect. 2010;138:1630-6. http://dx.doi.org/10.1017/S0950268810000695 
10. Homaira N, Rahman M, Hossain MJ, Nahar N, Khan R, Rahman M, et al. Cluster of Nipah virus infection, Kushtia District, Bangladesh, 2007. PLoS One. 2010;5:e13570. http://dx.doi.org/10.1371/journal.pone.0013570

11. Chadha MS, Comer JA, Lowe L, Rota PA, Rollin PE, Bellini WJ, et al. Nipah virus-associated encephalitis outbreak, Siliguri, India. Emerg Infect Dis. 2006;12:235-40. http://dx.doi.org/10.3201/ eid1202.051247

12. Sazzad HM, Hossain MJ, Gurley ES, Ameen KM, Parveen S, Islam MS, et al. Nipah virus infection outbreak with nosocomial and corpse-to-human transmission, Bangladesh. Emerg Infect Dis. 2013;19:210-7. http://dx.doi.org/10.3201/eid1902.120971

13. Chakraborty A, Sazzad HM, Hossain MJ, Islam MS, Parveen S, Husain M, et al. Evolving epidemiology of Nipah virus infection in Bangladesh: evidence from outbreaks during 2010-2011. Epidemiol Infect. 2016;144:371-80.

14. Chua KB, Lam SK, Goh KJ, Hooi PS, Ksiazek TG, Kamarulzaman A, et al. The presence of Nipah virus in respiratory secretions and urine of patients during an outbreak of Nipah virus encephalitis in Malaysia. J Infect. 2001;42:40-3. http://dx.doi.org/10.1053/jinf.2000.0782

15. Harcourt BH, Lowe L, Tamin A, Liu X, Bankamp B, Bowden N, et al. Genetic characterization of Nipah virus, Bangladesh, 2004. Emerg Infect Dis. 2005;11:1594-7. http://dx.doi.org/10.3201/ eid1110.050513

16. Rimi NA, Sultana R, Luby SP, Islam MS, Uddin M, Hossain MJ, et al. Infrastructure and contamination of the physical environment in three Bangladeshi hospitals: putting infection control into context. PLoS One. 2014;9:e89085. http://dx.doi.org/10.1371/ journal.pone. 0089085

17. Islam MS, Luby SP, Sultana R, Rimi NA, Zaman RU, Uddin M, et al. Family caregivers in public tertiary care hospitals in Bangladesh: risks and opportunities for infection control. Am J Infect Control. 2014;42:305-10. http://dx.doi.org/10.1016/ j.ajic.2013.09.012

18. Bhalla A, Pultz NJ, Gries DM, Ray AJ, Eckstein EC, Aron DC, et al. Acquisition of nosocomial pathogens on hands after contact with environmental surfaces near hospitalized patients. Infect Control Hosp Epidemiol. 2004;25:164-7. http://dx.doi.org/10.1086/502369

19. Boyce JM. Environmental contamination makes an important contribution to hospital infection. J Hosp Infect. 2007;65(Suppl 2):50-4. http://dx.doi.org/10.1016/S0195-6701(07)60015-2

20. Gurley ES, Montgomery JM, Hossain MJ, Bell M, Azad AK, Islam MR, et al. Person-to-person transmission of Nipah virus in a Bangladeshi community. Emerg Infect Dis. 2007;13:1031-7. http://dx.doi.org/10.3201/eid1307.061128

21. Hossain MJ, Gurley ES, Montgomery JM, Bell M, Carroll DS, Hsu VP, et al. Clinical presentation of Nipah virus infection in Bangladesh. Clin Infect Dis. 2008;46:977-84. http://dx.doi.org/ 10.1086/529147

22. Sazzad HM, Luby SP, Ströher U, Daszak P, Sultana S, Afroj S, et al. Exposure-based screening for Nipah virus encephalitis, Bangladesh. Emerg Infect Dis. 2015;21:349-51. http://dx.doi.org/ 10.3201/eid2102.141129

23. Daniels P, Ksiazek T, Eaton BT. Laboratory diagnosis of Nipah and Hendra virus infections. Microbes Infect. 2001;3:289-95. http://dx.doi.org/10.1016/S1286-4579(01)01382-X

24. Lo MK, Lowe L, Hummel KB, Sazzad HM, Gurley ES, Hossain MJ, et al. Characterization of Nipah virus from outbreaks in Bangladesh, 2008-2010. Emerg Infect Dis. 2012;18:248-55. http://dx.doi.org/10.3201/eid1802.111492
25. Hadley MB, Blum LS, Mujaddid S, Parveen S, Nuremowla S, Haque ME, et al. Why Bangladeshi nurses avoid 'nursing': social and structural factors on hospital wards in Bangladesh. Soc Sci Med. 2007;64:1166-77. http://dx.doi.org/10.1016/ j.socscimed.2006.06.030

26. Kramer A, Schwebke I, Kampf G. How long do nosocomial pathogens persist on inanimate surfaces? A systematic review. BMC Infect Dis. 2006;6:130. http://dx.doi.org/10.1186/1471-2334-6-130

27. Boone SA, Gerba CP. Significance of fomites in the spread of respiratory and enteric viral disease. Appl Environ Microbiol. 2007;73:1687-96. http://dx.doi.org/10.1128/AEM.02051-06

28. Hall CB. Nosocomial respiratory syncytial virus infections: the "Cold War" has not ended. Clin Infect Dis. 2000;31:590-6. http://dx.doi.org/10.1086/313960

29. Pirtle EC, Beran GW. Virus survival in the environment. Rev Sci Tech. 1991;10:733-48. http://dx.doi.org/10.20506/rst.10.3.570

30. Boone SA, Gerba CP. The prevalence of human parainfluenza virus 1 on indoor office fomites. Food Environ Virol. 2010;2:41-6. http://dx.doi.org/10.1007/s12560-010-9026-5

31. Brady MT, Evans J, Cuartas J. Survival and disinfection of parainfluenza viruses on environmental surfaces. Am J Infect Control. 1990;18:18-23. http://dx.doi.org/10.1016/0196-6553(90)90206-8

32. Hall CB, Douglas RG Jr, Geiman JM. Possible transmission by fomites of respiratory syncytial virus. J Infect Dis. 1980;141:98102. http://dx.doi.org/10.1093/infdis/141.1.98

33. Tollefson SJ, Cox RG, Williams JV. Studies of culture conditions and environmental stability of human metapneumovirus. Virus Res. 2010;151:54-9. http://dx.doi.org/10.1016/j.virusres.2010.03.018

34. de Wit E, Bushmaker T, Scott D, Feldmann H, Munster VJ. Nipah virus transmission in a hamster model. PLoS Negl Trop Dis. 2011;5:e1432. http://dx.doi.org/10.1371/journal.pntd.0001432

35. Naser AM, Hossain MJ, Sazzad HM, Homaira N, Gurley ES, Podder G, et al. Integrated cluster- and case-based surveillance for detecting stage III zoonotic pathogens: an example of Nipah virus surveillance in Bangladesh. Epidemiol Infect. 2015;143:1922-30. http://dx.doi.org/10.1017/S0950268814002635

36. Blum LS, Khan R, Nahar N, Breiman RF. In-depth assessment of an outbreak of Nipah encephalitis with person-to-person transmission in Bangladesh: implications for prevention and control strategies. Am J Trop Med Hyg. 2009;80:96-102.

37. Fogarty R, Halpin K, Hyatt AD, Daszak P, Mungall BA. Henipavirus susceptibility to environmental variables. Virus Res. 2008;132:140-4. http://dx.doi.org/10.1016/j.virusres.2007.11.010

38. de Wit E, Prescott J, Falzarano D, Bushmaker T, Scott D, Feldmann $\mathrm{H}$, et al. Foodborne transmission of nipah virus in Syrian hamsters. PLoS Pathog. 2014;10:e1004001. http://dx.doi.org/10.1371/journal.ppat.1004001

39. Levy JW, Suntarattiwong P, Simmerman JM, Jarman RG, Johnson K, Olsen SJ, et al. Increased hand washing reduces influenza virus surface contamination in Bangkok households, 2009-2010. Influenza Other Respi Viruses. 2014;8:13-6. http://dx.doi.org/10.1111/irv.12204

40. Gurley ES, Islam MS, Nahar N, Sultana R, Hossain MJ, Homaira N, et al. Behaviour change intervention to reduce caregivers' exposure to patients' oral and nasal secretions in Bangladesh. Int J Infect Control. 2013;9. http://dx.doi.org/10.3396/ijic.v9i2.017.13

Address for correspondence: Md Zakiul Hassan, Programme for Emerging Infections, Infectious Diseases Division, icddr,b, 68, Shaheed Tajuddin Ahmed Sarani, Mohakhali, Dhaka 1212, Bangladesh; email: zhassan@icddrb.org 